\title{
Survey: NTL Detection in Electricity Energy Supply
}

\author{
Jibran Rasheed Khan \\ Department of Computer \\ Science - UBIT, University of \\ Karachi, Karachi, Pakistan
}

\author{
Farhan Ahmed Siddiqui \\ Department of Computer \\ Science - UBIT, University of \\ Karachi, Karachi, Pakistan
}

\author{
Rehan Rasheed Khan \\ PAF-KIET College of \\ Engineering, \\ Karachi, Pakistan
}

\begin{abstract}
The most essential asset of any country that can boost its development or can destroy it, is electricity. Electricity theft prevention or non-technical loss detection has become major problem around the globe for every developed or under develop country to maintain its status in global society. Every month and every year many researchers, scholars and university students presented their studies, ideas and proposed their electric management system for prevalent of nontechnical energy loss detection in transmission line. The core objective of this survey is to highlight the existing solutions, their effectiveness in terms of performance and accuracy and their applicability. This will help in finding a diverse and reliable solution, understanding what others possible methodologies and techniques can be adopted in order to overcome current transmission supply challenges and improve the existing solution that can promptly address electricity prevention issues.
\end{abstract}

\section{Keywords}

Electricity Theft, Energy Prevention, Non-Technical Loss (NTL) Detection, Machine Learning, Artificial Intelligence, Smart Meter, AMI

\section{INTRODUCTION}

The rapid revolution in information technology transforms our societies and living standards, connects us with the global world on our finger tips, changes business nature and provides other countless benefits that save time and comfort our lives. Although these technological advances have kept us away from the Stone Age with the fast and unstoppable speed to cloud world, they also make us dependent on electricity. Nowadays, our environment, lives and business are highly equipped with electrical and electronics devices and everyday works are completely depend upon the availability of electricity.

Today, the need of electricity has become the baseline of every single task. The extensive involvement of electric equipment, transforming things into electronic devices and their use in day to day routine work make it first essential requirement for industries, factories, business and educational sectors. Similarly, it also has become a significant element which plays an important role in country status, development, dealing and collaborating with other countries that also have power to damage or destroy any country more than to facilitate anyone.

All generated electricity can never be fully transmitted to end users due to the some technical and non-technical loss. In broad concept, there are four categories of electricity loss is expressed as fraud, directly stealing power, billing irregularities, and unpaid bills [1]. The technical loss is the electrical power dissipation occurs to due to the internal resistance and emission in end points, devices during power generation, transmissions and distribution process. This type of loss cannot be easily calculated and it is difficult to estimate exactly what amount of energy is being destroyed in this process and at which point major loss occurs. The technical loss cannot be stopped. While the non-technical energy loss, which is also commonly term as NTL and considered as T\&D loss (Transmission and Distribution Loss), can be determined by various type of methods. NTL is mainly due to the electricity theft fraud, stealing power (by any means or way), billing irregularities, and unpaid bills [1].

Now, in current circumstances, electricity is a key input in many production processes. Hence its continuous supply is crucial. The biggest challenge for any underdeveloped or developed country around the globe is the prevention of electricity energy theft [1]. Energy theft not only the rising price in electricity charges but also influences on many other factors such as inflation, unemployment, load-shading, disturbs routine of industries, factories and other businesses, rise in debts of power energy companies, as well as having a high impact on economical state of country. 


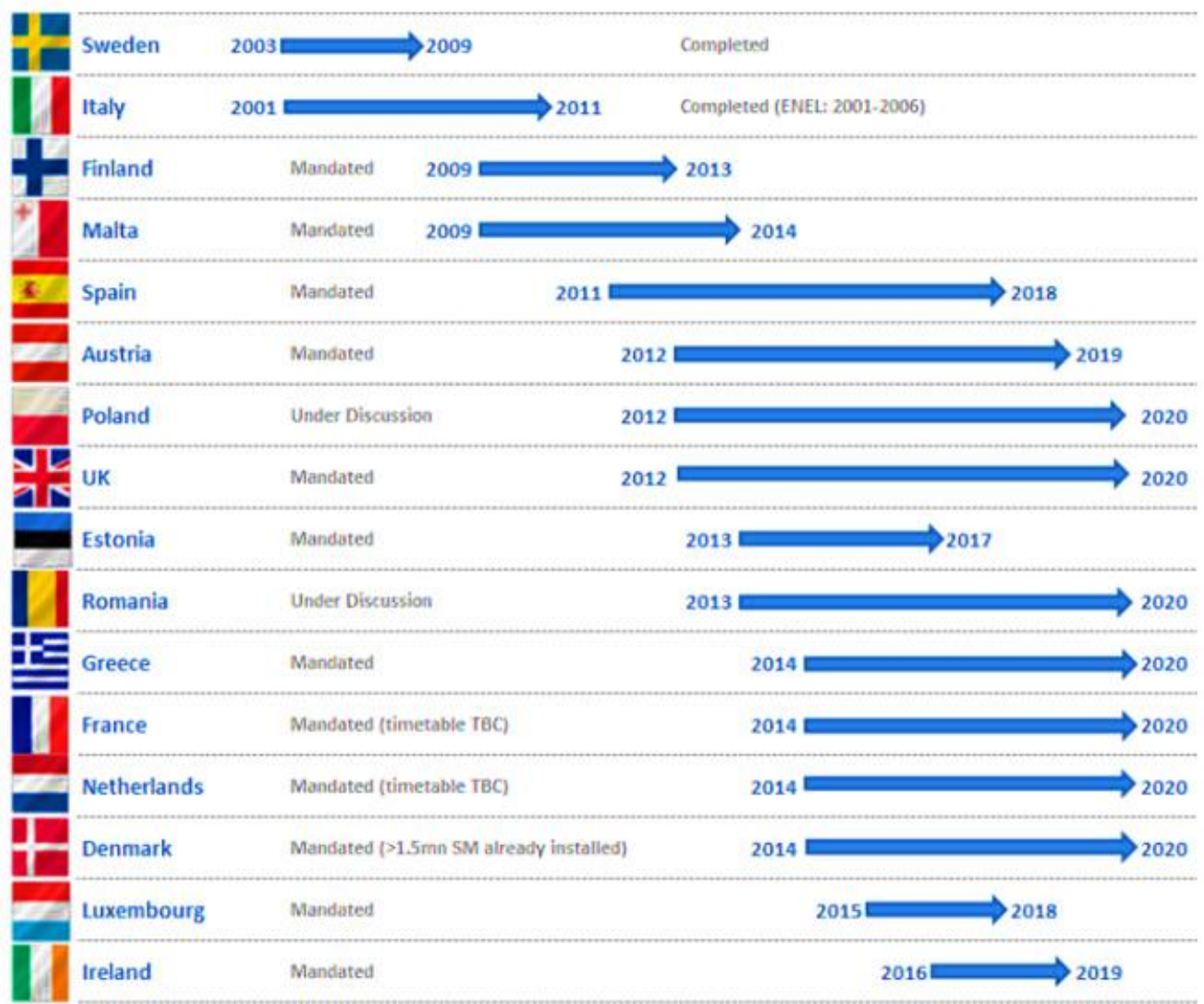

Fig 1: The 16 countries that plan to rollout smart meters in next 5 years [6]

Every year NTL brutally damage not only the power sector company's revenue but also significantly effects on energy resources and economy of the country. This NTL costs billions of dollars to every country including Pakistan, India, US, UK, Brazil, Malaysia and others countries as well. Recently, NTL reported that it covers up to $40 \%$ of total energy [2]. According to the JPS, of the 26.6 percent system losses registered in 2014 , approximately 17.0 percentage points represent non-technical losses [1]. Specifically, in Pakistan, it was recorded around $17.03 \%$ of total energy which costs hundreds of billion dollars, as per the financial year 2013 [3]. There are about $\$ 25$ billion of losses annually in the world [4]. In order to overcome the NTL loss, the world is spending a huge amount in research projects to discover the reliable solution that encounter the electricity theft detection and its prevention like smart grid system. There were 90 smart meeting project rollouts in Europe during the mid of year 2012. Some important projects are listed in the Figure 1 [5] [6].

According to the JRC report as stated in [7], 459 smart grid projects have been developed in 47 countries by 2014, out of which 211 of them are R\&D (Research and Development) projects with a total budget of around $€ 830$ million. While rest of others include demonstration and deployment projects with a total budget of around $€ 2320$ million. This is comparatively more than $50 \%$ of all projects that are initiated in Denmark, Germany, Italy, Austria, United Kingdom, France and Spain.

[8] Performed comprehensive survey on papers(s)/survey(s) published on electricity theft issues related topics. It showed some interesting stats about researcher or countries concern in this area and can easily predict the need to address these issues in mean time. Table 1 represents the frequency of publication by year and categorical proportion of solutions.

Table 1. Publication per year since 2010 [8]

\begin{tabular}{|c|c|}
\hline Year & Publications \\
\hline 2000 & 0 \\
\hline 2001 & 0 \\
\hline 2002 & 1 \\
\hline 2003 & 0 \\
\hline 2004 & 0 \\
\hline 2005 & 1 \\
\hline 2006 & 2 \\
\hline 2007 & 5 \\
\hline 2008 & 4 \\
\hline 2009 & 6 \\
\hline 2010 & 13 \\
\hline 2011 & 14 \\
\hline 2012 & 12 \\
\hline 2013 & 16 \\
\hline
\end{tabular}

It can be observed that since 2006 with rapid growth of technology, it became an attraction of researchers and a critical 
issue such as electricity demand rises along with a large ratio of electricity supply wastes in NTL and T\&D loss that must need to be diminished in mean time.

In this cause, every year, the researchers around the globe present their ideas, solution and design to prevalent illegal power consumption by utilizing different tools, techniques, methodologies and concepts with incorporating information technology. The [7] stated that the universities, research centers, consultancies and distribution system operators are the best represented in all smart grid, electricity control and management related projects. They are the forefront and in numbers, in terms of investment, providing workshop for experiment and studies, practical environment in such researches, ideas, project, their development and implementations.

\section{RESEARCH PROCESS}

This research is primary based on the most recent papers and surveys from which the comparatively high percentage of papers/surveys have been published either in during the present year 2016 or the past year 2015, while some of papers/surveys are from the years 2010, 2012 and 2014 due to high relevancy of their research.

The search keyword used during this research included; Energy Theft, Non-Technical loss, Energy Loss, T\&D Loss, Smart Grid, Smart Meter, AMI, Challenges/Issues in Electricity Monitoring, Challenges/Issues in Smart Grid and Power Theft. These research survey(s)/paper(s) are taken from the world renowned websites' (ResaerchGate, ScienceDirect, IEEE, Elsevier and Springer, MDPI) journals and other journals including; Cambridge journal, Transactions on Power Delivery, IJIRCCE, APSIPA Transactions on Signal and Information Processing, JETAE, IOSRJEEE, IERJ, IJEDR, Tsinghua Science and Technology, IJETT, IJCEIT, IJRITCC, IJARECE, and IJSR.

\section{STANDING METHODS AND SOLUTIONS FOR NTL PREVENTION}

The study and solutions are not limited in this research area. There are many ways to deal with a single problem.

The [4] [9], described the advantages of smart meter over the electromechanical in terms of electricity theft monitoring and usability along with defining data communication process in smart meter. [4] also discussed some mathematical models that can refine the results using known artificial intelligence model. [5] [6] [9] Emphasized the need of smart grid and smart meter infrastructure, their trends in the current circumstances. While in [10], the author presented analytical framework with the help of three machine learning algorithms by utilizing and focusing their studied on untypical load profiling technique. He used this technique as standard for detecting, monitoring and investigating any irregular and illegal activities by means of outlier methods. Authors used two types of load profile as normal and abnormal to classify consumer. The profiling mechanism, however, has been rejected by many researchers as its behavior is not suitable for such purpose and varies by profile to profile.

[1], defined some methods that can be used to measure the interruptions cost of electricity in his study:

A) The Production Loss Approach, this aids in calculating the production loss of each unit and easy to calculate.

B) Customer Surveys, these techniques are further divided into two section, first is Willingness to Pay
(WTP) that facilitates to understand the consumer nature and the regions those need and afford uninterruptable supply. While the other Willingness to Accept (WTA) assist in identifying which consumers, or region can bear the electricity shortfall.

C) Captive Generation Approach, supports in deciding what the alternative source of energy is and how it can be utilized to minimized or maintain the production cost.

D) Case Studies, provides the deep insight of the historical event and solutions that mitigate in a certain situation or scenario.

[11] [12] [13]Discussed the various reason of illegal use of electricity consumptions in Turkey, India and other countries. They used constant elasticity model with IV-GMM and 3SLS techniques and the Feasible Generalized Least Squares (FGLS) regression model for analysis, respectively. They consider some particular cases and performed analysis. The analysis highlighted some important factors that had high and direct influence on electricity theft. This includes education, income, social capital, rural population rate, temperature index, and agricultural production rate. It is also noticed that privatization of power sector companies results in less NTL ratio. According to the [12] [13]privatization of electricity sector reduced the distribution losses by half in seven years in Chile and only three years in Argentina. This also benefits in breaking of the link between indulge politicians or political influences and the corruption in the power sector. These determinants are not restricted to these countries only, but also can be considered for other states.

The [14] discussed three schemes to detect and control over electricity theft and by comparing their proposed model with other two solutions. Authors presented schemes including the AMI or Smart Meter, prepaid energy system, and central observer mechanism. The AMI or smart meter is two-way communication system that control theft using load management system. While the second model proposed the interfacing with AMI meter to provide consumer with prepaid energy card that needs to be swapped each month and upon ending credit, consumer need to recharge it before utilizing electricity through meter. If card has no credit or not been swapped the meter automatically turn off the supply for that consumer until and unless recharge and swap again. Against these two existing solutions, authors presented their model as "central observer system". This is a middle ware meter between the consumer and distribution point that divide central observation of group or number of meters which would be easier to monitor and identified specific segment. (Load Balancing)

In [15] [16] both presented hardware based circuit solution under the context of theft detection. According to the [15] it is stated that by utilizing the presented circuit we can detect the power theft done in two various ways like A) Phase By-passing $\&$ B) Overloading of the system done using different ways and the same can be stopped by tripping the supply for overload condition and indicating the phase by-pass condition. Both [15] [16] are similar in their solutions except [16] utilizing the "Tactile Sensing" device to detect any interference in meter. (Load Balancing)

The [17] [18] also proposed a hardware and software based solution by interfacing with meter and detecting on the basis of power deliver and power consume by utilizing ZigBee and 
other wireless technologies. Although, the author stated that the designed system is fully effective and workable but they did not mention any significance results. They also failed to mention at what ratio the presented system will detect and notify theft. Their prosed work related with each other, seem like similar work in different titles. The [19] further continue the [17] [18] work with little amendment. While the core calculating criteria for [17] [18] and [19] are based on load balancing techniques.

The [20] highlighted the unaddressed and critical point in his study that no other noticed earlier. He described that in the current electric system, the majority of transmission and distribution loss occurs between the distributions and consumer end-point or smart meter as shown in Figure 1. The author proposed a system designed to integrate indicated hardware with a smart grid in order to act accordingly. Instead of supply load difference calculation and his solution working on unit consumption difference at both hand. This only workable in one condition, when the actual load is more than the distribution.

The [21] only work founded during the survey which worked on technical loss detection to estimate and find NTL. This model calculates the amount of supply at particular time in distribution transformer and smart meter that would be easy to estimate each user consumption. The proposed algorithm has some constraints and was experimented on a typical simplified condition. This based on two type user demand profiles, seasonal and random; in seasonal all user profile treated as equal in nature or in other words static, while in other case is generated by random component that taking from the autoregressive process. Although the results are considerable, but it would differ in the real world as this carried out in the absence of actual information and details.

In [22] discussed the various machine learning algorithms and their use, possibilities and what would be more accurate in prevention and detection of NTL with smart meter. The [23] proposed methodology for electricity tampering detection uses the information obtained from the smart meter, in order to automate the detection and localization process. The smart metering infrastructure and intelligent substation are considered in the topology and are essential for the proposed electricity theft detection.

\section{RESULTS}

The researchers discussed several artificial intelligence (AI) and machine learning algorithms that utilized different country's dataset of different power sectors companies with different attributes and in different circumstances. The Table 3 [2], summarized them and reflect some key elements that cannot be neglected in determining the NTL preventions in future work.

Table 2. Performance measure of AI in NTL detection [2]

\begin{tabular}{|l|c|c|c|c|c|c|}
\hline \multicolumn{1}{|c|}{ Model } & \#Cust $^{\mathbf{a}}$ & Acc $^{\mathbf{b}}$ & Pre $^{\mathbf{c}}$ & Rec $^{\mathrm{d}}$ & AUC $^{\mathrm{e}}$ & Prop $^{\mathrm{f}}$ \\
\hline SOM & $2 \mathrm{~K}$ & 0.93 & 0.85 & 0.98 & - & - \\
\hline NN & $22 \mathrm{~K}$ & 0.87 & 0.65 & 0.29 & - & - \\
\hline SVM (Gauss) & 1,350 & 0.98 & - & - & - & - \\
\hline Bool rules & $700 \mathrm{~K}$ & - & - & - & 0.47 & $5 \%$ \\
\hline
\end{tabular}

\begin{tabular}{|c|c|c|c|c|c|c|}
\hline Fuzzy rules & $700 \mathrm{~K}$ & - & - & - & 0.55 & $5 \%$ \\
\hline SVM (linear) & $700 \mathrm{~K}$ & - & - & - & 0.55 & $5 \%$ \\
\hline Bool rules & $700 \mathrm{~K}$ & - & - & - & 0.48 & $20 \%$ \\
\hline Fuzzy rules & $700 \mathrm{~K}$ & - & - & - & 0.55 & $20 \%$ \\
\hline SVM (linear) & $700 \mathrm{~K}$ & - & - & - & 0.55 & $20 \%$ \\
\hline Neuro-fuzzy & $20 \mathrm{~K}$ & 0.68 & 0.51 & - & - & - \\
\hline SVM & $<400$ & - & - & 0.53 & - & - \\
\hline Genetic SVM & 1,171 & - & - & 0.62 & - & - \\
\hline SVM + fuzzy & $100 \mathrm{~K}$ & - & - & 0.72 & - & - \\
\hline SVM (Gauss) & $<400$ & 0.77 & - & 0.64 & - & - \\
\hline Decision tree & N/A & 0.99 & - & - & - & - \\
\hline OPF & 736 & 0.90 & - & - & - & - \\
\hline SVM (Gauss) & 736 & 0.89 & - & - & - & - \\
\hline SVM (linear) & 736 & 0.45 & - & - & - & - \\
\hline $\mathbf{N N}$ & 736 & 0.53 & - & - & - & - \\
\hline SVM & $5 \mathrm{~K}$ & 0.96 & - & - & - & - \\
\hline KNN & $5 \mathrm{~K}$ & 0.96 & - & - & - & - \\
\hline NN & $5 \mathrm{~K}$ & 0.94 & - & - & - & - \\
\hline Regression & 30 & - & - & 0.22 & - & $1 \%$ \\
\hline Regression & 30 & - & - & 0.78 & - & $2 \%$ \\
\hline Regression & 30 & - & - & 0.98 & - & $3 \%$ \\
\hline Regression & 30 & - & - & 1 & - & $4-10 \%$ \\
\hline Rough Sets & N/A & 0.93 & - & - & - & - \\
\hline
\end{tabular}

Where $\mathrm{a}, \mathrm{b}, \mathrm{c}, \mathrm{d}$, e, and $\mathrm{f}$ are Number of customers in the database used, Accuracy, Precision, Recall, Area under the receiver operating characteristic curve, and NTL/theft detection proportion respectively. By the above table it can be easily observed that the results are varying by size, attributes and algorithm used. Whereas, the detection proportion also differ in different approaches with limits from 1 to 20 percent. Most common detection ratio is set to be at $5 \%$ in majority of existing solutions. Furthermore, many solutions and studies are missing the accuracy. It is also observed that the same dataset by different algorithms produced relatively same results, while the results differ with different data sets. These, software based solutions (AI, machine learning) will not be able to counter any theft if it is within their tolerance level such as 5\% loss or theft occur in the absence of legitimate consumer. If we narrow down this tolerance level to $1 \%$ appeared in some solution, it will always notify supply theft. All the above mentioned 
software based AI solution may be feasible within specific region and area or for small region but not practically seem to be appropriate for city or country level as number of users per distribution point is not fix

Table 3. Solution Proportion by Type

\begin{tabular}{|c|c|c|c|}
\hline Type & $\%$ & Solution & Method \\
\hline $\begin{array}{l}\text { Idea or } \\
\text { Concept }\end{array}$ & 23 & $\begin{array}{l}\text { Ideas without any practices that } \\
\text { can be followed to build } \\
\text { solutions }\end{array}$ & - \\
\hline Theory & 24 & $\begin{array}{l}\text { Consists of surveys, case studies, } \\
\text { prevailing solutions that can be } \\
\text { helpful in improving existing } \\
\text { solutions. }\end{array}$ & \multirow{3}{*}{ 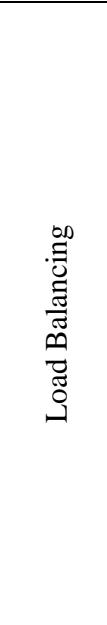 } \\
\hline Hardware & 17 & $\begin{array}{l}\text { Proposed electronics, electrical } \\
\text { and interface based solution for } \\
\text { supply management and } \\
\text { monitoring in smart grid system } \\
\text { (AMI, smart meter). }\end{array}$ & \\
\hline Software & 36 & $\begin{array}{l}\text { It consists of APIs, Tools, } \\
\text { software based management } \\
\text { system, desktop and web } \\
\text { applications with incorporation } \\
\text { of smart grid system. Mainly and } \\
\text { mostly working on AI and } \\
\text { machine learning algorithms }\end{array}$ & \\
\hline
\end{tabular}

The statistics of Table 2 is taken from [8], the solutions and techniques is based on preceding and current studies. It is important to note that almost every mentioned solution of monitoring \& detecting electricity theft are working on "Load Balancing" techniques either by incorporating hardware, software (including AI methods) or by interfering (Non-AI methods using circuits, sensors etc.) with smart meter, while using same data transmission \& communication medium.

\section{CONCLUSION}

Electricity management and theft detection is the primary concern of every underdeveloped and developed country around the globe that directly impact on several factors such as country's economy, industries and business revenue. The rise in NTL and increasing shortfall of electricity energy cost billions of dollars every year, which results in discouraging investors to do business in Pakistan and downgrading country status. In this survey we have reviewed various existing proposed solutions including ideas, conceptual model, software based scheme, architectural design, interfacing with smart grid or AMI meter and hardware based solutions.

The survey also identified that all discussed solutions that have been presented till date are either working on the machine learning algorithms or advance circuit based solutions to find out the theft or energy leakage in end to end power transmission supply on the basis of "Load Balancing" technique. The transmission and data communication is done by utilizing different wireless technologies and integrating with the smart grid or with Advance Metering Infrastructure (AMI). All solutions, however, have some threats and limitations in terms of accuracy and others factors. Also the existing solutions are dependent upon smart grid, which is itself a complex network infrastructure and possessing challenges \& issues in data transmission, communication and cyber security.

On contrary, researchers accepted that there is still a room for better solution and more research is needed in this area for appropriate and generic solution that is universally accepted. With the introduction of smart grids and distribution utilities, the large amount of data is obtained through end users / customers and by this we create some model / analytical applications. By monitoring abnormalities and utilization patterns we can find out the suspicious areas / customers. In future, we can also use some classification and clustering techniques to find out the usage patterns and non-malicious changes in usage pattern that is more generic (implemented anywhere) and able to deal with all types of complex problems with high level of accuracy and raise maximum performance.

\section{REFERENCES}

[1] F. B. Lewis, "Costly 'Throw-Ups': Electricity Theft and Power Disruptions," The Electricity Journal, vol. 28, no. 7, p. 118-135, 2015.

[2] R. S. F. B. Patrick Glauner, "The Challenge of NonTechnical Loss Detection using Artificial Intelligence: A Survey," IEEE TRANSACTIONS ON POWER DELIVERY, vol. XX, p. 8, 2016.

[3] C. S. Miguel Barrientos, "electric-power-transmissionand-distribution-losses," IndexMundi, 2015. [Online]. Available:

http://www.indexmundi.com/facts/pakistan/electricpower-transmission-and-distribution-losses. [Accessed 1 October 2016]

[4] N. J. A. M. S. M. R. U. Q. M. Anas, "Minimizing Electricity Theft using Smart Meters in AMI," August 2012. [Online]. Available: https://www.researchgate.net/publication/230657229.

[5] L. H. D. d. 1. V. I. A. Noelia Uribe-Pérez, "State of the Art and Trends Review of Smart Metering in Electricity Grids," Applied Sciences, vol. 6, no. 3, pp. 68-91, 2016.

[6] Eurelectric, "Utilities: Powerhouses of Innovation Full Report," 8 May 2013. [Online]. Available: http://www.eurelectric.org/media/79178/utilties_powerho use_of_innovation_full_report_final-2013-104-0001-01e.pdf. [Accessed 310 2016].

[7] S. G. M. Ilhami Colak, "A survey on the critical issues in smar tgrid technologies," Renewable and Sustainable Energy Reviews, vol. 54, p. 396-405, 2016.

[8] F. Ghulam Rasool n, "A Systematic Literature Review On Electricity Management Systems," Renewable and Sustainable Energy Reviews, pp. 976-983, 2015.

[9] WCIR, "Theft / Loss Detection Solutions," WIPRO, Bangalore, 2011.

[10] S. D.Dangar, "Electricity Theft Detection Techniques for Distribution System in GUVNL," JEDR, pp. 1-18, 2014.

[11] Ç. Yurtseven, "The causes of electricity theft: An econometric analysis of the case of Turkey," Utilities Policy, vol. 37, pp. 70-78, 2015.

[12] E. G. Vasundhara Gaur, "The determinants of electricity theft: An empirical analysis of Indian State," Energy Policy, vol. 93, p. 127-136, 2016.

[13] T. B.Smith, "Electricity theft: a comparative analysis," Energy Policy, vol. 32, p. 2067-2076, 2004.

[14] S. A. Sana Sardar, "Detecting And Minimizing Electricity Theft: A Review," JETAE, vol. 1, no. 1, pp. 8-12, 2016. 
[15] P. Jadeja, "Detection and Instantaneous Prevention of Power Theft," IOSR-JEEE, vol. 10, no. 1, pp. 1-3, 2015.

[16] G. S. K. M. Kalaivani, "GSM Based Electricity Theft Identification in Distribution System," IJETT, vol. 8, no. 10, pp. 512-516, 2014

[17] P. S. B. G. V. A. Prof. N. S. Labhde, "Detection of Power Theft Using ZigBee Technology," IERJ, vol. 2, no. 1, pp. 121-124, 2016

[18] H. g. s. s. K. Dr. Pramod Sharma, "WIRELESS ELECTRICITY THEFT DETECTION AND MONITORING," IJARECE, vol. 5, no. 4, pp. 994-998, 2016.

[19] D. S. M. M. S. Aditi Komajwar, "Wireless Power Theft Monitoring System In Energy Meter," in National Conference on Knowledge, Innovation in Technology and Engineering (NCKITE), Raipur, Chhattisgarh, India, 2015.

[20] P. Y. H. P. Parvin Shikalgar, "Power Theft Identification Using Smart Grid Technology," IJRITCC, vol. 3, no. 1, pp. $259-263,2015$.

[21] N. D., W. Z., E. A., S. H., S. K., M. T. and T. K., "Smart Meter Data Analysis for Power Theft Detection," Machine Learning and Data Mining in Pattern Recognition, vol. 7988, pp. 379-389, 2013.

[22] A. K. H. J. S. A. M. M. Pratap Jumale, "Survey: Electricity Theft Detection Technique," IJCEIT, vol. 8, no. 2, p. 30-35, 2016.

[23] J. B. J. F. G. C. W. L. K. P. Kadurek, "Theft detection and smart metering practices and expectations in the Netherlands," in Innovative Smart Grid Technologies Conference Europe (ISGT Europe), 2010.

[24] A. M. K. Saurabh M. Jain, "A Survey on Power Theft Detection," IJIRCCE, vol. 4, no. 1, pp. 509-511, 2016.

[25] L. W. V. D. S.S.S. Depuru, "Electricity Theft : Overview, issues, prevention and a smart meter based approach to control theft," Energy Policy, vol. 39, p. 1007-1015, 2010.

[26] R. L. Y. W. J. L. C. S. a. X. (. S. Rong Jiang, "EnergyTheft Detection Issues for Advanced Metering Infrastructure," TSINGHUA SCIENCE AND TECHNOLOGY, vol. 9, no. 2, pp. 105-120, 2014.

[27] L. W. V. D. R. C. G. S.S.S. R Depuru, "High performance computing for detection of electricity theft," Electrical Power and Energy Systems, vol. 47, p. 21-30, 2013.

[28] M. Y. M.-A. Moath Jarrah, "A hierarchical optimization model for energy data flow," vol. 53, p. 190-200, 2015.

[29] M. L. A. Maria Lorena Tuballa, "A review of the development of Smart Grid technologies," Renewable and Sustainable Energy Reviews, vol. 59, p. 710-725, 2016.

[30] K.-C. L. V. O. L. X. H. a. C.-C. J. K. Miles H.F. Wen, "A survey on smart grid communication system," APSIPA Transactions on Signal and Information, vol. 4, no. 5, pp. $1-20,2015$
[31] Y. Kabalci, "A survey on smart metering and smart grid communication," Renewable and Sustainable Energy Reviews, vol. 57, p. 302-318, 2016.

[32] J. H. H. R. B. R. B. H. S. David Grochocki, "AMI Threats, Intrusion Detection Requirements and Deployment Recommendations," in SmartGridComm.2012.6486016, 2012.

[33] R. Michael Emmanuel, "Communication technologies for smart grid applications : A survey," Journal of Networkand Computer Applications, vol. 74, p. 133-148, 2016.

[34] P. Siano, "Demand response and smart grids - A survey," Renewable and Sustainable Energy Reviews, vol. 30, p. 461-478, 20014.

[35] M. E. Kantarci, "Energy-Efficient Information and Communication Infrastructures in the Smart Grid: A Survey on Interactions and Open Issues," IEEE Communications Surveys \& Tutorials, vol. 17, no. 1, pp. 179-197, 2015.

[36] H. S. I. A. E. DavorSvetinovic, "Integrated smart grid systems security threat model," Information Systems, vol. 53 , p. $147-160,2015$.

[37] A. L. R. A. N. F. Mohd Adib Sarijari, "Interference issues in Smart Grid Home Area Network to enable Demand Response and Advanced Metering Infrastructure: survey and solutions," OIJI, vol. 1, pp. 59-71, 2012.

[38] F. Jamil, "On the electricity shortage, price and electricity theft nexus," Engergy Policy, vol. 54, p. 267-272, 2013.

[39] X. D. S.-H. S. E. B. Mohamed Nabeel, "Scalable end-toends ecurity for advanced metering infrastructures," Information Systems, vol. 53, p. 213-223, 2015.

[40] H. A.-R. Omar Ellabban, "Smart grid customers' acceptance and engagement :An overview," Renewable and Sustainable Energy Reviews, vol. 65, p. 1285-1298, 2016.

[41] I. C. G. F. K. D. R. Bayindir, "Smart grid technologies and applications," Renewable and Sustainable Energy Reviews, vol. 66, p. 499-516, 2016.

[42] B. S. G. P. S. M. Aditya Gaura, "Smart City Architecture and its Applications based on IoT," Procedia Computer Science, vol. 52, p. 1089 - 1094, 2015.

[43] J. B. J. F. G. C. W. L. K. P. Kadurek, "Theft detection and smart metering practices and expectations in the Netherlands," in Innovative Smart Grid Technologies Conference Europe (ISGT Europe), 2010 IEEE PES, 2010.

[44] L. M.Camarinha-Matos, "Collaborative smart grids - A survey on trends," Renewable and Sustainable Energy Reviews, vol. 65, p. 283-294, 2016.

[45] Reducing Technical and Non-Technical Losses in the Power Sector, 2009. 